\title{
1 Copper(II) Gluconate Boosts the Anti-SARS-CoV-2 Effect of Disulfiram In Vitro
}

2 Luyan Xu, ${ }^{[\mathrm{a}],[\S]}$ Wei Xu, ${ }^{[\mathrm{b}],[\S]}$ Simeng Zhao, ${ }^{[\mathrm{c}]}$ Suwen Zhao, ${ }^{[\mathrm{c}]} \mathrm{Lu} \mathrm{Lu},{ }^{*[\mathrm{~b}]}$ and Bo-Lin Lin ${ }^{*[\mathrm{a}]}$

3 [a] School of Physical Science and Technology, ShanghaiTech University, 393 Middle Huaxia Road,

4 Pudong new district, Shanghai, 201210, P. R. China. E-mail: $\underline{\text { linbl@ shanghaitech.edu.cn }}$

5 [b] Key Laboratory of Medical Molecular Virology (MOE/NHC/CAMS), Shanghai Institute of

6 Infectious Disease and Biosecurity, School of Basic Medical Sciences, Fudan University, Shanghai

7 200032, P. R. China. E-mail: $\underline{\text { lul@ fudan.edu.cn }}$

8 [c] iHuman Institute and School of Life Science and Technology, ShanghaiTech University, 393

9 Middle Huaxia Road, Pudong new district, Shanghai, 201210, P. R. China.

10 [§] Co-first authors

11

12 
13 Abstract: Disulfiram is a 70-year-old anti-alcoholism drug, while copper(II) gluconate $\left(\mathrm{Cu}(\mathrm{Glu})_{2}\right)$ is a

14 commonly used food additive or copper supplement. Here we disclose that the combination of

15 disulfiram and copper(II) gluconate drastically enhances the anti-SARS-CoV-2 activity at the cellular

16 level as compared to disulfiram or copper(II) gluconate alone. A 1:1 mixture of disulfiram and copper(II)

17 gluconate shows an $\mathrm{EC}_{50}$ value of $154 \mathrm{nM}$ against SARS-CoV-2 at the cellular level, much lower than

18 the $17.45 \mu \mathrm{M}$ reported for disulfiram alone. Notably, previous clinical trials have shown that a

19 combination of $250 \mathrm{mg}$ disulfiram $(0.843 \mathrm{mmol})$ and $8 \mathrm{mg}$ copper(II) gluconate $(0.0176 \mathrm{mmol})$ oral

20 capsules per day is well tolerated (NCT03034135, NCT00742911). A preliminary mechanism is

21 proposed to rationalize the observed promotional effect. 
We observed that the inhibitory effect of disulfiram (DSF) or copper(II) gluconate alone on SARS-

$23 \mathrm{COV}-2$ at the cellular level was $67.59 \%$ and $66.98 \%$ at $10 \mu \mathrm{M}$, respectively, while the inhibitory effect

24 of a fresh 1:1 mixture of disulfiram and copper(II) gluconate was over 99\% at $10 \mu \mathrm{M}$ (Table 1). Further

25 measurements showed that the $\mathrm{EC}_{50}$ of the 1:1 combination of disulfiram and copper(II) gluconate

26 against SARS-COV-2 at the cellular level was $154 \mathrm{nM}$ (Figure 1), significantly lower than that of

27 disulfiram alone $(17.45 \mu \mathrm{M}){ }^{1}$

28 Table 1. Inhibitory ratio of various chemicals by single-point inhibition assay at $10 \mu \mathrm{M}$ onto

29 SARS-COV-2 at the cellular level, determined by qRT-PCR analysis. $\mathrm{n}=3$ biological replicates.

\begin{tabular}{|c|c|c|c|c|c|c|c|c|c|}
\hline $\begin{array}{c}\text { Concentration } \\
(\mathbf{1 0} \boldsymbol{\mu M})\end{array}$ & \multicolumn{3}{|c|}{ Cu(Glu) } & \multicolumn{3}{c|}{ DSF } & \multicolumn{3}{c|}{ DSF+Cu(Glu) } \\
\hline Inhibition (\%) & 75.86 & 61.94 & 63.14 & 65.47 & 63.79 & 73.52 & 99.87 & 99.85 & 99.87 \\
\hline
\end{tabular}

As shown in Figure 1, the mixture of disulfiram and copper(II) gluconate had much improved inhibitory activity of against SARS-CoV-2 infection with an $\mathrm{EC}_{50}$ of $154 \mathrm{nM}$ (Figure 1). The results showed that viral RNA levels of the mixture of disulfiram and copper(II) gluconate were significantly

34 lower than that of the non-mixture groups (disulfiram or copper(II) gluconate). Notably, previous 35 clinical trials have shown that a combination of $250 \mathrm{mg}$ disulfiram $(0.843 \mathrm{mmol})$ and $8 \mathrm{mg}$ copper(II) 36 gluconate $(0.0176 \mathrm{mmol})$ oral capsules per day is well tolerated (NCT03034135, NCT00742911). ${ }^{2,3}$

UV-vis spectroscopy revealed that the appearance and growth of an absorption peak at $433 \mathrm{~nm}$

38 from the 1:1 mixture of disulfiram and copper(II) gluconate over time, indicating the gradual formation

39 of diethyldithiocarbamic acid cupric salt, $\mathrm{Cu}(\mathrm{DDC})_{2}$ (Figure 2). Dynamical light scattering

40 spectroscopy showed that the resultant $\mathrm{Cu}(\mathrm{DDC})_{2}$ formed nanoparticles with the sizes of several

41 hundred nanometers at the early stage (Figure 3). The particles slowly became larger than 1 micron and 42 eventually precipitated out of the solution. 


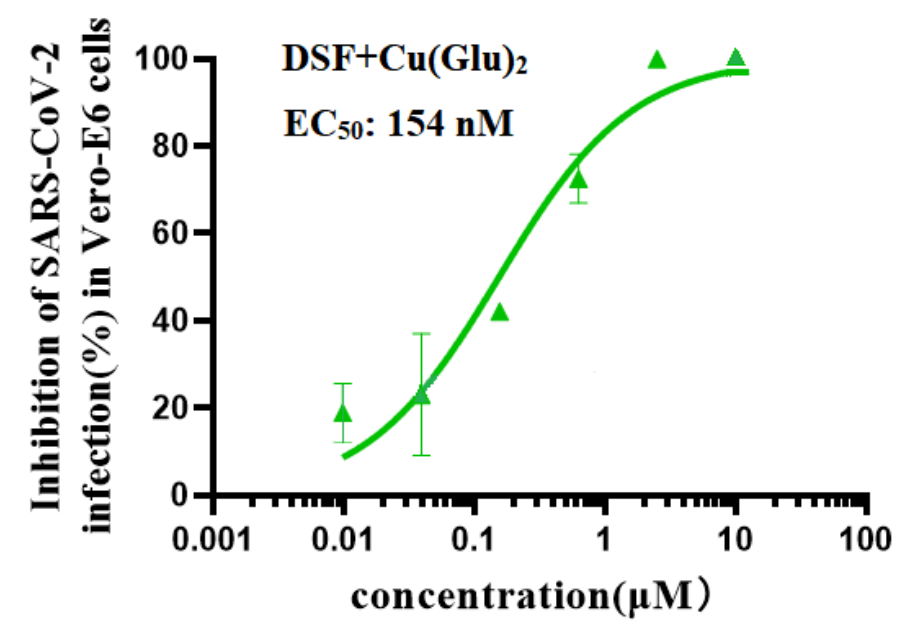

44 Figure 1. Dose-response curve for $\mathrm{DSF}+\mathrm{Cu}(\mathrm{Glu})_{2}$, determined by qRT-PCR analysis, All data are

45 shown as mean \pm s.e.m., $\mathrm{n}=3$ biological replicates. 
bioRxiv preprint doi: https:/doi org/101101/2021.09.17.460613: this version posted October 1, 2021. The copyright holder for this preprint (which was not certified by peer review) is the author/funder, who has granted bioRxiv a license to display the preprint in perpetuity. It is made available under aCC-BY-NC-ND 4.0 International license.
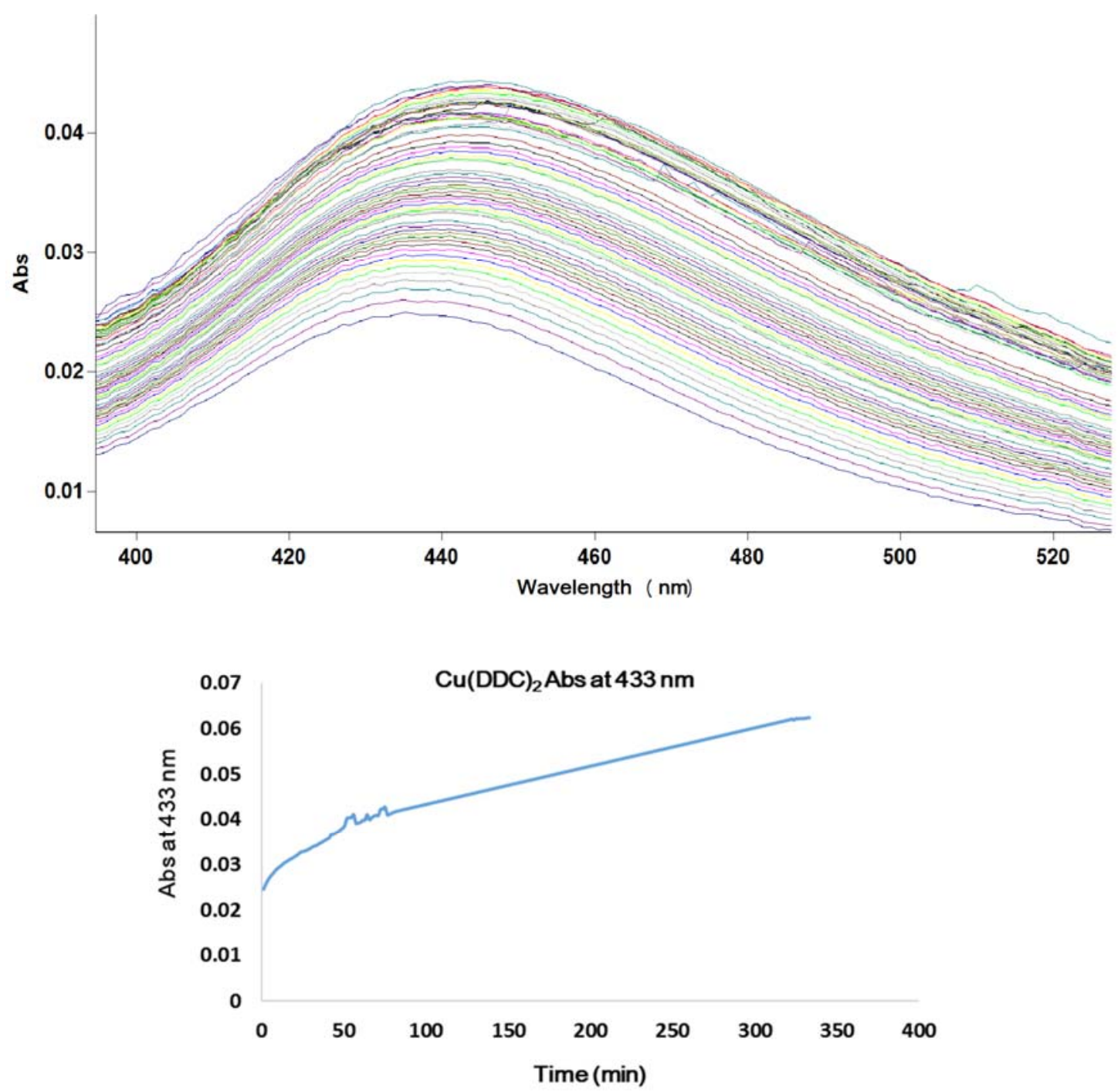

47 Figure 2. The appearance and growth of an absorption peak at $433 \mathrm{~nm}$ from the 1:1 mixture of

48 disulfiram and copper(II) gluconate over time.

49

50

51

52 


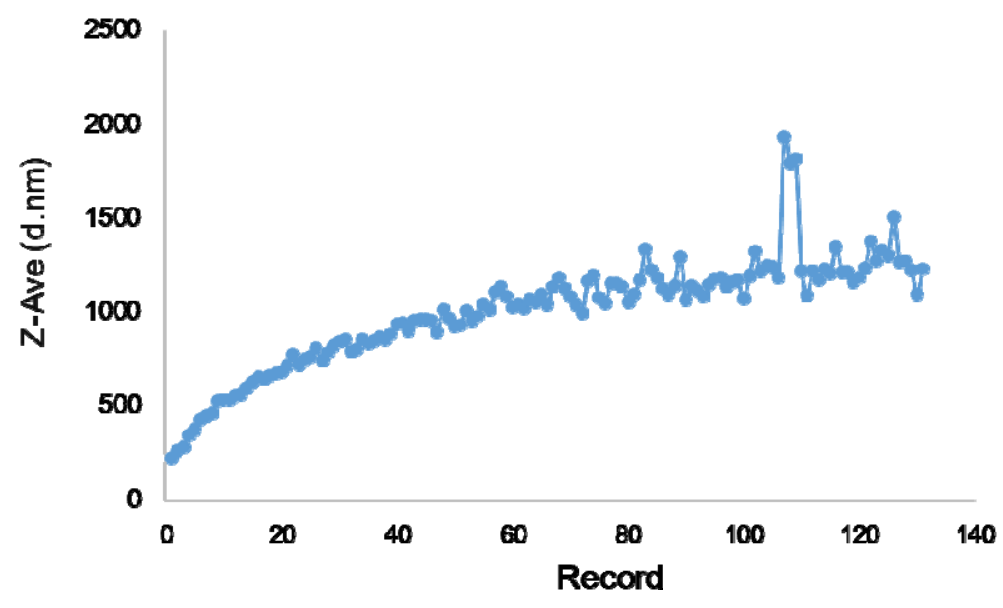

Figure 3. The growth of $\mathrm{Cu}(\mathrm{DDC})_{2}$ particles from the 1:1 mixture of disulfiram and copper(II)

55 gluconate over time.

Notably, a comparison of some approved drugs shows that the combination of disulfiram and

$\mathrm{Cu}(\mathrm{Glu})_{2}$ has a relatively low $\mathrm{EC}_{50}$ value against $\mathrm{SARS}-\mathrm{CoV}-2$ at the cellular level. However, further

experiments, especially carefully designed clinical trials, are necessary before any conclusion can be

draw on whether such combination can be used to treat COVID-19 or not.

Finally, we postulate that the boosting effect of $\mathrm{Cu}$ onto the anti-SARS-CoV-2 activity of

62 disulfiram at the cellular level might be attributed to the in situ formation of $\mathrm{Cu}(\mathrm{DDC})_{2}$, which has been

63 shown to possess an extraordinary ability to selectively oxidize zinc thiolate in the presence of thiols.

64 Since zinc finger domains are present in several important SARS-CoV-2 enzymes crucial for the virus

65 proliferation (e.g. RdRp), ${ }^{4} 5 \mathrm{Cu}(\mathrm{DDC})_{2}$ may impair the function of these enzymes to inhibit SARS-

66 CoV-2 proliferation via selective oxidation of the zinc thiolate sites of zinc finger domains even in the

67 presence of a high concentration of glutathione. ${ }^{6}$ 
73 Table 2. $\mathrm{EC}_{50}$ values of various approved drugs against SARS-CoV-2 at the cellular level.

\begin{tabular}{|c|c|c|}
\hline Approved Drug & $\begin{array}{l}\mathbf{E C}_{50}(\mu \mathrm{M}) \\
(\text { Vero })\end{array}$ & DOI \\
\hline $\mathrm{DSF}+\mathrm{Cu}(\mathrm{Glu})_{2}$ & 0.154 & This work \\
\hline Boceprevir & 15.57 & $10.1038 / \mathrm{s} 41467-020-18233-\mathrm{x}$ \\
\hline Disulfiram & $\sim 10$ & $10.1038 / \mathrm{s} 41586-020-2223-\mathrm{y}$ \\
\hline Clofazimine & 0.31 & $10.1038 / \mathrm{s} 41586-020-2577-1$ \\
\hline Atazanavir & 2.0 & \multirow{3}{*}{ 10.1021/acsptsci.0c00074 } \\
\hline Nelfinavir & 1.13 & \\
\hline Boceprevir & 1.9 & \\
\hline Remdesivir & 0.72 & \multirow{8}{*}{ 10.1126/science.abg5827 } \\
\hline Desloratadine & 0.7 & \\
\hline Flupentixol & 0.76 & \\
\hline Ttrimipramine & 1.5 & \\
\hline Lapatinib & 1.6 & \\
\hline Benztropine & 1.8 & \\
\hline Azelastine & 2.4 & \\
\hline Masitinib & 3.2 & \\
\hline
\end{tabular}




\section{Methods}

\section{Anti-viral activity assays}

77 A clinical isolate of SARS-CoV-2(SARS-CoV-2 / SH01 / human / 2020 / CHN, GenBank MT121215).

78 The virus was purified by phagocytosis, reproduced in Vero-E6 cells, and stored in $-80 \square$ for future use.

79 All tests involving virus infection are strictly conducted at a biosafety level-3. Gradient-diluted drugs

80 were mixed with SARS-CoV-2 (100TCID50) virus (the virus was diluted with serum-free DMEM

81 medium) with the same volume, and incubated at $37^{\circ} \mathrm{C}$ for 1 hour. In the 96 -well plates (vero-E6 cells

82 were $1 \times 10^{4}$ / well), the supernatant was removed, $100 \mu \mathrm{L}$ of the above drug/virus mixture was added,

83 and the cells were incubated at $37^{\circ} \mathrm{C}$ for 1 hour. At the end of incubation, $100 \mu \mathrm{L}$ of DMEM+2\% FBS

84 was added per well. After being placed in a cell incubator for further culture for 48 hours, the cell

85 supernatant was collected for subsequent detection. Viral RNA was extracted from the cell supernatant

86 using TRIzol LS reagent (Invitrogen) according to the manufacturer's instructions. One-step

87 PrimeScript ${ }^{\mathrm{TM}}$ RT Reagent Kit (Takara, Japan, Cat.\#RR064A) Kit were used for quantitative real-time

88 PCR. The reaction procedure of RT-PCR was: Reverse transcription: $95 \square$ 10s, $42 \square 5 \mathrm{~min}$; PCR

89 reaction: (95 $\square 5 \mathrm{~s}, 56 \square$ 30s, $72 \square 30$ s)*40 cycles. The detection was carried out with a BIO-RAD

90 quantitative fluorescence PCR instrument. The primers were: SARS-COV-2-N-F:

91 GGGGAACTTCTCCTGCTAGAAT, SARS-CoV-2-N-R: CAGACATTTTGCTCTC AAGCTG,

92 SARS-CoV-2-N-probe: 5'-FAM- TTGCTGCTGCTTGACAGATT-TAMRA-3'.

93 


\section{References}

95 1. Sargsyan, K.; Lin, C. C.; Chen, T.; Grauffel, C.; Chen, Y. P.; Yang, W. Z.; Yuan, H. S.; Lim, C., Multi96 targeting of functional cysteines in multiple conserved SARS-CoV-2 domains by clinically safe Zn-ejectors. Chem. Sci. 2020, 11 (36), 9904-9909.

2. Huang, J.; Chaudhary, R.; Cohen, A. L.; Fink, K.; Goldlust, S.; Boockvar, J.; Chinnaiyan, P.; Wan, L.; Marcus, S.; Campian, J. L., A multicenter phase II study of temozolomide plus disulfiram and copper for recurrent temozolomide-resistant glioblastoma. J. Neurooncol. 2019, 142 (3), 537-544.

3. Kelley, K. C.; Grossman, K. F.; Brittain-Blankenship, M.; Thorne, K. M.; Akerley, W. L.; Terrazas, M. C.; Kosak, K. M.; Boucher, K. M.; Buys, S. S.; McGregor, K. A.; Werner, T. L.; Agarwal, N.; Weis, J. R.; Sharma, S.; Ward, J. H.; Kennedy, T. P.; Sborov, D. W.; Shami, P. J., A Phase 1 dose-escalation study of disulfiram and copper gluconate in patients with advanced solid tumors involving the liver using Sglutathionylation as a biomarker. BMC Cancer 2021, 21 (1), 510.

4. Xu, L.; Tong, J.; Wu, Y.; Zhao, S.; Lin, B.-L., Targeted Oxidation Strategy (TOS) for potential inhibition of coronaviruses by Disulfiram - a 70-year old anti-alcoholism drug. . ChemRxiv 2020, https://doi.org/10.26434/chemrxiv.11936292.v1.

5. Xu, L.; Tong, J.; Wu, Y.; Zhao, S.; Lin, B. L., A computational evaluation of targeted oxidation strategy (TOS) for potential inhibition of SARS-CoV-2 by disulfiram and analogues. Biophys. Chem. 2021, 276, 106610.

\section{Acknowledgements}

115 We thank Dr. Qian Wang of Core Facility of Microbiology and Parasitology of Fudan University. We 116 are very grateful to Dr. Di Qu, Xia Cai and Shan Su from Biosafety Level 3 Laboratory in Shanghai 117 Medical College of Fudan University for their continuous support. This work was supported by the 118 National Natural Science Foundation of China (No. U2032132).

\section{Competing interest}

